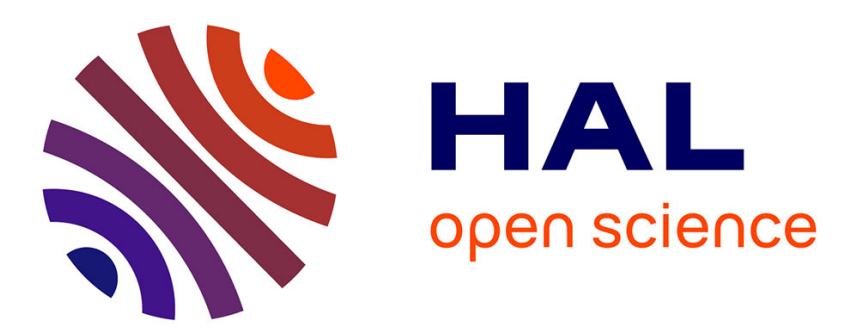

\title{
Brain tumor epilepsy: A reappraisal and six remaining issues to be debated.
}

Laurent Vercueil

\section{To cite this version:}

Laurent Vercueil. Brain tumor epilepsy: A reappraisal and six remaining issues to be debated.. Revue Neurologique, 2011, 167 (10), pp.751-61. 10.1016/j.neurol.2011.08.007 . inserm-00628902

\section{HAL Id: inserm-00628902 https://www.hal.inserm.fr/inserm-00628902}

Submitted on 4 Oct 2011

HAL is a multi-disciplinary open access archive for the deposit and dissemination of scientific research documents, whether they are published or not. The documents may come from teaching and research institutions in France or abroad, or from public or private research centers.
L'archive ouverte pluridisciplinaire HAL, est destinée au dépôt et à la diffusion de documents scientifiques de niveau recherche, publiés ou non, émanant des établissements d'enseignement et de recherche français ou étrangers, des laboratoires publics ou privés. 
Brain Tumor Epilepsy : A reappraisal and six remaining issues to be debated.

Epilepsie et Tumeurs cérébrales : Une mise au point et six questions encore en débat

Auteur :

Laurent Vercueil, MD PhD

EFSN

Psychiatry and Neurology Pole

CHU Grenoble

Grenoble Institut of Neurosciences

INSERM U836

38043 Grenoble, France

courriel : Ivercueil@chu-grenoble.fr

tel : +33476765561

fax : +33 476765928 


\section{Abstract}

Epilepsy associated with brain tumors presents with specific features deserving medical attention : 1) although commonly reported in patients with brain tumor, either as revealing mode or as a remote complication, limited knowledge is available regarding their epidemiology, clinical evolution, surgical outcome, physiopathology and treatment, providing only clues for clinical management. 2) seizures appear even more threatening for patients and care-givers, providing seizures could meant tumor progression and recurrence. This factor adds to the negative impact epilepsy carry on quality of life measures. 3) pharmacotherapy is complicated by the use of chemotherapy and interaction between antiepileptic drugs and antineoplastic agents are frequent and potentially harmful. 4) the high incidence of epilepsy enlights the question of prophylaxy with antiepileptic drugs, in patients without seizures, or during the perioperative period, and after surgery, when gross total resection has been achieved. This article attempts to provide the reader with an overview of brain tumor epilepsy in its specific aspects and to comment on some remaining issues.

Keywords : Epilepsy, Brain Tumors, Antiepileptic drugs, glioblastoma, glioma, seizures. 


\section{Résumé}

L'épilepsie associée à la présence d'une tumeur cérébrale, par de nombreux aspects, soulève des problèmes spécifiques qui justifient qu'elle soit traitée en tant que telle. 1) D’une manière générale, les études la concernant sont relativement limitées, ou d'une utilisation rendue difficile par les évolutions des classifications histologiques des tumeurs qui font que des suivis pratiqués sur des groupes de patients à une période donnée peuvent avoir été biaisés de façon importante par l'inclusion de patients hétérogènes. 2) A l'échelle de l'individu, les crises épileptiques soulèvent immanquablement la question angoissante de la progression éventuelle de la tumeur ou de sa récidive, et cette connotation péjorative s'ajoute au retentissement bien connu de l'épilepsie en général, sur la qualité de vie. 3) L'utilisation conjointe des traitements antiépileptiques et des agents chimiothérapeutiques est à l'origine de problème d'interaction, nuisant à l'efficacité ou à la tolérance des uns et des autres. 4) les questions du traitement prophylactique, régulièrement soulevées et discutées dans la littérature, justifiées par l'incidence élevée des crises épileptiques au sein de cette population, concernent aussi bien les patients n'ayant jamais présenté de crise, que la couverture éventuelle en période périopératoire, ou l'attitude à adopter, après la chirurgie d'exérèse, lorsque la cause éventuelle de l'épilepsie a été considérée éliminée. Ce travail présente une revue générale de la question des épilepsies associées aux tumeurs cérébrales et discute certains points particuliers qui sont encore en débat.

Mots clés : Epilepsie, crises épileptiques, tumeurs cérébrales, glioblastome, gliome, médicament antiépileptique 


\section{Abbreviations}

AEDs : antiepileptic drugs

BTE : Brain Tumor Epilepsy

DNET : Dysembryoplastic neuroepithelial tumor

EEG : Electroencephalogramm

G2G : Grade II Glioma

GBM : Glioblastoma

GG : Ganglioglioma

MRI : Magnetic Resonance Imaging 


\section{1-Introduction}

Epilepsy substantially impairs quality of life. Unpredictability of the fits, lifethreatening episodes, antiepileptic drugs (AEDs) side effects, even in seizure-free patients (Auriel, Landov et al. 2009), sleep disorder and anxiety (Alanis-Guevara, Pena et al. 2005), disease-related social stigma (Baker, Jacoby et al. 1997) and, significantly, comorbid depression (Boylan, Flint et al. 2004) (Cramer 2002) may contribute to this severe impact. Brain tumor patients, who are prone to present with epileptic seizure and epilepsy as remote symptomatic complications, could be even more vulnerable to this impact (Klein, Engelberts et al. 2003), since each seizure could be interpretated by the patient and his caregivers as a progression (or a reccurrence) of the tumor and as such, carry a pejorative overtone. Actually, epilepsy could be present at disease onset, promoting the discovery of the tumor, or may affect all stages of the disease, including end-life palliative care (Dupont 2008). Near all patients with primary brain tumour, and a substantial proportion of patients with metastatis, will present with epilepsy, underscoring the magnitude of the problem, exemplified by the report of enzyme-inducing AEDs interference with chemotherapy. This article is an attempt to present an overview of the topic and to address several remaining issues.

\section{2- Epilepsy and Neoplasms : General considerations}

\section{2-1. A key definition}

According to the revised International League Against Epilepsy definition of epilepsy (Fisher, van Emde Boas et al. 2005), epilepsy diagnosis requires either the recurrence of seizures in the absence of provoking factors (« unprovoked » seizure), or a single seizure if associated with the presence of any factor that can predispose 
to future seizure, for example, an epileptogenic brain lesion such as a tumor. This consideration should lead a neurologist or neurosurgeon to consider that, in a patient with brain tumor, any single epileptic seizure means epilepsy. This is an important point to consider with respect to pharmacotherapy, since it is thus presumed that a patient presenting with one seizure will require antiepileptic drug treatment as if already suffering from epilepsy. In this review, epileptic seizure and epilepsy will be used synonymously, although the occurrence of « true» acute symptomatic seizure in patients with brain tumour cannot be minimized and should not be overcome (Beghi, Carpio et al.).

\section{2-2 Clinics}

There is little argument to consider clinics of seizure as a specific feature of Brain Tumor Epilepsy (BTE). According to current view, patients with BTE are supposed to present with localization-related seizure, depending on the localization of the epileptogenic zone (Rossetti and Kaplan), whatever the nature of the epileptogenic lesion. However, some ictal features have been suggested to be more frequent in BTE than in other causes of epilepsy, such as olfactory auras, rapid and frequent secondary generalizations, postictal paralysis or some rare type of seizure (Hamilton and Kernick 2007). Admittedly, complex partial seizures is the commonest clinical presentation of tumors affecting the temporal lobe (Hamilton and Kernick 2007; Ruban, Byrne et al. 2009), although olfactory aura may be more suggestive (but not pathognomonic) for a tumoral etiology (Chen, Shih et al. 2003). Rare cases of ictal asystole with collapses related to tumoral temporal lobe epilepsy (van der Sluijs, Renier et al. 2004) or diffuse glioma (Sikkel and Batrick 2007) have been reported, however without specificity. Interestingly, apneic seizures have been reported in infants with temporal lobe tumors (Miyagawa, Sotero et al. 2007). In 
conclusion, despite some current clinical practice general considerations, it should be aknowledged that no ictal feature could be considered specific for BTE.

\section{2-3 Epidemiology}

Tumors associated with epilepsy include oligodendroglioma, astrocytomas, metastatic tumors, meningiomas, glioblastomas multiforme, dysembryoplastic neuroepithelial tumors and gangliogliomas. Rarer brain tumors could also be responsible for epilepsy, to various degree. Overall, it is usually considered that about one third of patients with brain tumors will develop epileptic seizure, rising to $50 \%$ if the location of the tumor is supratentorial and involves one hemisphere (Black 1991; Black 1991). Actually, brain tumor types influences epidemiological datas, with diverse age-specificity (some tumors affect preferentially young patients, others an elderly population), varying degree of epileptogenicity, brain location, etc..(figure 1). Usually, it is considered that epilepsy incidence in gliomas ranges between 30 and $80 \%$ with a lower frequency in high grade gliomas (Wrensch, Minn et al. 2002; Chang, Potts et al. 2008). Indeed, seizures represent a major revealing mode for low grade glioma (Chang, Potts et al. 2008), but during the follow up, even high grade tumor may exhibit a high rate of epilepsy (Liigant, Haldre et al. 2001; Hamilton and Kernick 2007; Lynam, Lyons et al. 2007).

\section{FIGURE 1 ABOUT HERE}

Accordingly, in a retrospective database study, although epilepsy as the presenting sign was more frequent in low-grade vs. high-grade gliomas $(69.7$ vs. $52 \%, P=$ 0.087 ), a total of $80 \%$ of patients with high-grade gliomas developed seizures as compared to 75,8\% with low-grade (van Breemen, Rijsman et al. 2009), $81 \%$ in another study (Chang, Potts et al. 2008). New onset seizure dramatically increased 
the risk of brain tumor for global population, even more (twice) for patients aged 60 to 69 years (Hamilton and Kernick 2007). Brain tumors increased new-onset epilepsy risk in patients older than $66(\mathrm{OR}=2.14,95 \% \mathrm{Cl}=1.46-3.13)$ according to a large veteran database study (Pugh, Knoefel et al. 2009).

Brain tumors represented $15 \%$ of the etiologies reported for epilepsies amenable to surgery in China (Xiao, Huang et al. 2004), $28 \%$ in a case series of surgically treated partial drug-resistant epilepsy in Grenoble, France (Pasquier, Peoc et al. 2002) $27 \%$ in a German reference center where only temporal lobe epilepsy were taken into account (Blumcke 2009). In a study of 247 patients with temporal lobe epilepsy, tumors were found in 33\%, the second leading cause after malformations of cortical development (Tassi, Meroni et al. 2009). Another report mentioned 14\% of tumoral etiologies among adults with mesial temporal lobe epilepsy (Soeder, Gleissner et al. 2009). Brain tumors could even be more frequent in children with temporal lobe epilepsy, as suggested by surgical case series (Sinclair, Wheatley et al. 2001). However, seizure are uncommon as a revealing mode of brain tumors in children, accounting for only $10,2 \%$ of a case series, where over symptoms appeared to predate epilepsy (Ibrahim and Appleton 2004). On the other hand, among children under age 3 , epilepsy could represent a major mode of revelation $(71 \%)$ in patients with hemispheric supratential tumors (Gaggero, Consales et al. 2009) Even at end-of-life period, epilepsy is consistently reported (Krouwer, Pallagi et al. 2000 ), affecting about $30 \%$ of patients according to a study of 324 patients with brain tumor in a palliative care unit (Pace, Di Lorenzo et al. 2009). Although this brief epidemiological review appears to provide some valuable informations, it should be emphasized that two main sources of data should be distinguished : 1) patients with refractory epilepsy leading to surgery in specialized 
epilepsy surgery units, where young patients and low grade tumors predominate, and 2) patients with brain tumors followed in neurooncology units, where surgery aimed to reduce tumor volume, regardless of epileptogenic peritumoral tissue. This consideration is important for many issues, including the planing of antiepileptic drugs withdrawal after surgery, for example. Table 1 summarizes the main epilepsy incidences observed either as revealing mode or as long term complication, depending on tumor types.

\section{TABLE 1 ABOUT HERE}

\section{2-4 Pathophysiology of BTE}

Mechanisms of tumor-related epileptogenesis remain poorly understood, but some facts could enlighten epidemiological findings : i) epilepsy is a gray matter disease, secondary to an imbalance between excitatory and inhibitory inputs, explaining why aggressive white matter neoplasms (glioblastoma, lymphomas) could be silent for long time, ii) epileptogenesis, via aberrant plasticity, requires time to develop, thus favouring low grade above high grade tumors. Although neoplastic tissue may be the initiation site of seizure activity, this could only be the case for tumors including elements issued from neuronal cell lines, such as gangliogliomas or dysembryoblastic neuroepithelial tumors (see below). On the other hand, a growing intracranial lesion alters both structurally and functionally the surrounding « safe » brain tissue with oedema, vascular insufficiency, inflammation, and release of metabolically active molecules, hence promoting seizure activity (Kohling, Senner et al. 2006). The involved mechanisms are certain to be multifactorial, including genetic contribution and depend on tumor histology and location (figure 2), integrity of the blood brain barrier, and characteristics of the peritumoral environment (Schaller and 
Ruegg 2003; Shamji, Fric-Shamji et al. 2009).

\section{FIGURE 2 ABOUT HERE}

Recently, a change in GABA transmission properties was evidenced in human peritumoral epileptogenic tissue, leading to epileptogenicity (Conti, Palma et al. 2011). Also, downregluation of glutamine synthetase has been shown in GBM associated with epilepsy as compared to GBM without epilepsy (Rosati, Marconi et al. 2009) and it should be reminded that disruption of the BBB per se could induce epileptic seizures (Marchi, Angelov et al. 2007). Thus, convergences of different pathways appear to lead to seizure, and interventions should target each of them.

\section{2-5 Antiepileptic Pharmacotherapy}

Among medical problems requiring specific treatment in patients with brain tumor, seizures represent the most frequent, before peritumoral oedema, increasing intracranial pressure, medication side effects, venous thromboembolism, fatigue and cognitive dysfunction (Wick, Menn et al. 2005; Wen, Schiff et al. 2006). In patients with single seizures, regardless of the etiology, immediate anti-epileptic drugs (AEDs) treatment increases time to recurrent seizures compared to delayed treatment, without differences with respect to quality of life (Marsons A $2005 ; 365: 2007-2013$ ), thus AED treatment is recommended to be started after the first seizure in the setting of brain tumor, as already quoted (Soffietti, Baumert et al. ; Rossetti and Stupp). Among partial epilepsies, BTE is usually responsive to drug treatment, with a rate of drug-resistance comparitively lower (approximatively $35 \%$ ) than some other etiologies, such as hippocampal sclerosis (Stephen, Kwan et al. 2001). However, it should be noted that dual pathology is not uncommon, as hippocampal sclerosis was found in $8 \%$ of patients with temporal lobe tumors, for example, thus potentially 
leading to apparent higher drug-resistant rates (Tassi, Meroni et al. 2009).

There is currently no consensus of which AEDs are most effective in BTE, and little data are available regarding the specific population affected by BTE, but interactions between AEDs, chemotherapeutic agents, and corticosteroids challenge the managing of seizures, so that AEDs that do not interfere with the cytochrome P-450 enzyme complex and have low protein binding should be preferable.

Accordingly, «traditional » AEDs, such as phenytoin, phenobarbital, carbamazepine, which are enzyme-inducing agents, can induce steroid metabolim and even decrease effective concentrations of antineoplastic agents (Rossetti and Stupp, 2010). Lamotrigine, proved to be superior to carbamazepine, gabapentin and topiramate in the SANAD study (Marson et al, 2007), could be a valuable option. Among new AEDs, Pregabalin (PGB) is a non-enzyme inducing antiepileptic drug showing promising effectiveness in BTE (Novy, Stupp et al. 2009). In another uncontrollled, retrospective study, oxcarbazepine (OCX) was better tolerated than previous « firstgeneration » AED (Maschio, Dinapoli et al. 2009), although the risk of cutaneous rash may be sensitized by radiotherapy (Maschio, Dinapoli et al.). Zonisamide had been studied as add-on therapy in patients with BTE (Maschio, Dinapoli et al. 2009) Levetiracetam (LEV) was recently introduced as an interesting alternative for BTE treatment (Wagner, Wilms et al. 2003). In a uncontrolled prospective study, LEV was shown to be well tolerated and provided a good seizure improvement in 17 patients with BTE (Usery, Michael et al., 2009). Further studies confirmed the good profile of LEV in BTE (Maschio, Dinapoli et al. ; Rosati, Buttolo et al. ; Maschio, Albani et al. 2006; Newton, Goldlust et al. 2006) and metastatic brain tumor epilepsy (Maschio, Dinapoli et al. ; Newton, Dalton et al. 2007). Several experts recommend use of LEV as first monotherapy in BTE (Rossetti and Stupp ; Vecht and Wilms ; Vecht and van 
Breemen 2006; van Breemen, Rijsman et al. 2009), although others still suggest valproic acid, lamotrigine and topiramate as first choice treatments (van Breemen, Wilms et al. 2007). Switch from traditionnal (PHT) to recent (LEV) AED has been proved to be safe in the postoperative period (Lim, Tarapore et al. 2009), while, on the other hand, shift from brand to generic LEV as been associated with seizure reccurrence (Armstrong, Choi et al. 2011). More recently, Lacosamide, as add-on therapy, showed promising results (Maschio et al. 2011).

The same considerations should apply for pediatric population, with further emphasis on LEV use (Ruggiero, Rizzo et al. ; Partap and Fisher 2009; Sogawa, Kan et al. 2009). In rare case, chemotherapy only (namely temozolomide) proved to improve epileptic seizure frequency (Ngo, Nei et al. 2006).

\section{3- Epilepsy in different brain tumors types}

\section{3-1 Grade II Glioma Epilepsy}

Adult grade II glioma (G2G) include astrocytomas, oligodendrogliomas and oligoastrocytomes (Louis, Ohgaki et al. 2007; Smits and Duffau 2011) and represent up to $30 \%$ of gliomas, affecting patients at a younger age than high grade glioma (figure 1). In G2G, focal neurological deficits are unusual, or develop over many years. Also, raised intracranial pressure is rare in patients with supratentorial tumors, while, as already quoted, seizure is the most presenting symptom of G2G, occurring in 70 to $90 \%$ of patients (van Breemen, Wilms et al. 2007; Chang, Potts et al. 2008). Involvement or proximity to the cortex is a key factor predicting seizures in G2G (Hwang, Lin et al. 2004), while frontal, parietal and insular locations are particularly involved (Chang, Potts et al. 2008). It is important to note that several studies have demonstrated that the slower the growth ot the tumor, the higher the risk of epilepsy 
(figure 2) (Beaumont and Whittle 2000) (Schaller and Ruegg 2003). In line with this consideration, oligodendroglioma carry a higher risk of epilepsy than astrocytoma, thus suggesting that functional rearrangement involving synaptic plasticity should be required in peritumoral tissue epileptogenicity (Schaller and Ruegg 2003). In a retrospective chart review, $81 \%$ of patients with G2G presented with at least one seizure (Chang, Potts et al. 2008), while in another study 88 among 101 patients with G2G had seizure at disease onset (Danfors, Ribom et al. 2009). In approximatively half of the patients with G2G and seizures, epilepsy appeared to be drug resistant (Chang, Potts et al. 2008) (Danfors, Ribom et al. 2009). As compared to other revealing clinical symptoms, seizure at onset is classicaly considered a good prognosis factor (van Veelen, Avezaat et al. 1998), perhaps because epilepsy allowed the discovery of little-sized tumors, as compared to silently growing deep tumors causing headache or neurological deficits when a substantial brain volume is already impaired. However, it has been recently underlined that inclusion of glioneuronal tumors and grade I glioma in so-called « low-grade glioma » population studies could have artificially improved the global outcome, which remains severe in « true » G2G patients, due to the unavoidable malignant transformation of the tumor (Smits and Duffau 2011).

A monocentric retrospective study of patients with insular $G 2 G$ and epilepsy suggested that surgery benefits included improvement in epilepsy (Taillandier and Duffau 2009). Gross total surgical resection is the major factor influencing postoperative seizure control in G2G (Englot, Berger et al.) (Kim, Yong Ahn et al. 2004).

\section{3-2 Glioblastoma Epilepsy}


Epilepsy affects 30 to $40 \%$ of patients with high-grade tumour during the course of the disease (Preusser, de Ribeaupierre et al. 2011), but may rarely reveal the tumour (Rossi, Figus et al.), especially in older patients, where new-onset epilepsy should promote the search for a brain lesion (Hamilton and Kernick 2007). However, despite this fact, it has also been shown that elderly patients with glioblastoma multiforme (GBM) are less prone to epilepsy than younger (Chaichana, Parker et al. 2009) . Few studies considered epilepsy with regard to GBM or other high grade glioma (Rosati, Tomassini et al. 2009). In this study population, epilepsy appeared to be more difficult to control in high grade than in low grade glioma, and was shown to be more frequent in GBM derived from a low grade tumour (so-called " secondary » GBM) compared to GBM de novo (« primary » GBM) (Rosati, Tomassini et al. 2009) . A bias could explain why high-grade tumor causing epilepsy are smaller than non epileptogenic high-grade tumor : as a revealing mode, epilepsy becomes rapidly clinically evident as compared to deep tumor that slowly, incidiously induces evolving cognitive or sensorymotor deficits (Lee, Wen et al. 2010).

Patients with GBM remained still prone to develop epilepsy, even after surgery and without previous seizures (Telfeian, Philips et al. 2001), while postoperative de novo seizure appears to be highly correlated with tumor recurence (Chaichana, Parker et al. 2009) (Rosati, Tomassini et al. 2009). Recently, a strong association between enzyme-inducing antiepileptic drugs use and negative outcome (survival rate, side effects) of patients with GBM was shown, suggesting that valproic acid could increased haematotoxicity and carbamazepine decreased efficacy of chemotherapy (Rosenow, Reif et al. ; Oberndorfer, Piribauer et al. 2005). This could further represent an argument supporting new generation of non-enzyme inducing agents as 
antiepileptic drug treatments (see pharmacotherapy section, above).

\section{3-3. Glioneuronal Tumor Epilepsy}

Dysembryoplastic neuroepithelial tumor (DNET) and ganglioglioma (GG) are the most epileptogenic of the brain tumors, with a rate of $100 \%$ and $85 \%$ of epilepsy, respectively, while other symptoms are usually lacking. DNETs are supposed to have a germinal origin, and gross total surgical resection usually lead to epilepsy cure. DNET is considered as one leading cause for drug-resistant focal epilepsy in children, but in a consecutive series of children operated for refractory epilepsy, ganglioglioma (GG) overweighted DNET (12 vs 7 among 24 patients) (Alexiou, Varela et al. 2009). GG are benign and slow-growing tumors found in patients of all ages, accounting for $1.3 \%$ of all brain tumors (Zentner et al., JNNP 1994). As already quoted, in young adults or children, GG represents a substantial part of refractory epilepsy leading to surgery. Histologically, GG is characterized by a mixture of dysplastic neuronas and glial cell elements, whereas the neoplastic component of the tumor is represented by the astroglial cells. Another characteristic of the tumor is the perivascular lymphocytic infiltration. The role of activated microglia in the associated epilepsy has been underlined by some authors (Aronica E, Louvel, 2005). Although included among the malformations of cortical development (MCD) with active proliferation and abnormal cell types, together with dysembryoplastic neuroepithelial tumors, focal cortical dysplasia, hemimegalencephaly and tuberous sclerosis complex, it has been suggested that GG could be issued from a dysplastic precursor lesion, with high intrinsic epileptogenicity as demonstrated by the presence of a hyperexcitable neuronal component (Aronica E, Boer Neuroscience 2008). Moreover, inflammatory response evidenced in these developmental tumors could 
also be involved in this respect (Ravizza et al., 2006; Aronica E, Louvel 2005). As for DNETs, GG associated epilepsy is usually resistant to antiepileptic drugs and offers a rather good seizure freedom rate after surgery. A systematic literature review showed that surgical intervention targeting GG in adults led to a higher rate of seizure control postoperatively when occurring less than 3 years after symptom onset (78\% vs 48\%) (Yang et al., J Clin Neuroscience 2011). In this review, no correlation was found between this duration and the gross total resection rate, thus underscoring the relevance of early surgery in such patients. In a systematic literature analysis regarding the effects of early surgical intervention on the clinical outcome of patients with ganglioglioma, seizure control was significantly improved when surgical intervention occurred less than 3 years after symptom onset $(78 \%$ versus 48\%; $p=0.0001$ ) (Yang, Chang et al.). Temporal location of ganglioglioma is frequently associated with seizure, and usually led to a good outcome after surgery (Im, Chung et al. 2002; Park, Kim et al. 2008). A lesionectomy (removal of the glioneuronal tumor) is associated with a favorable epilepsy outcome (Giulioni, Galassi et al. 2005; Giulioni, Gardella et al. 2006; Giulioni, Rubboli et al. 2009). Interestingly, both GG and DNETs have been associated with an unexpected high rate of postoperative psychiatric disorder, such as psychosis, paranoia or depression, that could suggest a residual functional role played by some elements within the tumor.

\section{3-4. Brain Metastasis Epilepsy}

Brain metastasis $(B M)$ is the most common malignancy of the nervous system. Survival is usually short, that can explain the relatively less frequent occurrence 
of epilepsy as compared to primary brain tumor, since epileptogenicity needs time to develop (see above, pathophysiological considerations). In a review of 1292 patients with brain metastasis, epilepsy represented a revealing symptom in $22 \%$ (Lagerwaard, Levendag et al. 1999) and in $21 \%$ in a previous study (Zimm, Wampler et al. 1981). Thus, it is nowadays considered that less than one third of patients with BM suffer from epilepsy. Primary lung tumors account for $50 \%$ of all metastatic brain tumors. Of lung cancer patients who survive for more than 2 years, $80 \%$ will have brain metastases. However, melanoma has an increased incidence among other systemic cancers in terms of metastasizing to the brain with more than half of of patients with melanoma who will have brain metastasis, eventually multiple metastasis, thus increasing the risk of epilepsy. Another factor enhancing epilepsy risk is hemorrhagic complication, which is also common in melanoma metastasis, explaining why melanoma carry a higher risk for epilepsy, with about an half of patients with melanoma brain metastasis exhibiting seizure during the course of disease (Byrne, Cascino et al. 1983).

\section{3-5 Other brain tumors epilepsy}

Meningiomas are associated with epilepsy in 30 to $40 \%$ of patients, but notably, there is a dramatic increase in seizure rate after surgical resection, even in patients without seizure preoperatively (Mangano, McBride et al. 2002). Hypothalamic hamartoma $(\mathrm{HH})$ often cause a refractory epilepsy syndrome associated with cognitive and psychiatric troubles (Striano, Striano et al. 2009). The clinical hallmarks of the lesion include gelastic seizures and precocious puberty in young patients. Surgical ablation of $\mathrm{HH}$ is not always possible, and gamma-knife surgery could be considered. Epilepsy also may reveal intraventricular tumor (neurocytoma, choroid 
plexus papilloma) which has been suspected to be partly involved in the epileptogenic process (lannelli and Pieracci 2008), as could it be also the case for macroprolactinoma in rare patients (Deepak, Daousi et al. 2007). Isolated increased unilateral amygdala volume in temporal lobe epilepsy is not uncommon, but has been shown to be of non tumoral origin (Soeder, Gleissner et al. 2009; Mitsueda-Ono, Ikeda et al.). Although incidentaly radiological findings, intracranial lipoma are very rarely considered to be involved (one case among five) in epilepsy (Loddenkemper, Morris et al. 2006)

\section{4- Remaining issues to be discussed}

\section{4-1. Could prophylactic antiepileptic drug treatment still be in debate ?}

After the American Academy of Neurology published a recommendation discouraging the use of prophylactic treatment (Glantz, Cole et al. 2000), other meta-analysis explored the issue whether antiepileptic drugs (AEDs) should be prescribed to patients with brain tumors who have no history of seizures, leading to the same conclusion regarding phenytoin, valproic acid and phenobarbital (Sirven, Wingerchuk et al. 2004). No difference between treatment interventions (phrophylactic antiepileptic drug) and the control groups in preventing a first seizure in participants with brain tumors could be evidenced in one more original study (Forsyth, Weaver et al. 2003) or in a systematic literature review (Tremont-Lukats, Ratilal et al. 2008) . Moreover, the risk of an adverse event was higher for participants on AEDs than for those without (Tremont-Lukats, Ratilal et al. 2008). Despite this amount of evidence, until recently, it remains a current practice to treat glioma patients with AEDs in the absence of seizure, according to a recent survey among neurosurgeons (Siomin, Angelov et al. 2005). It should be note, that a recent systematic review 
also discourage the use of AEDs in patients with brain metastasis without seizure (Mikkelsen, Paleologos et al.).

Another prophylactic issue regards the use of AEDs during the perioperative period (Lwu, Hamilton et al.). Some teams suggested the use of oxcabarmazepine to reduced the risk of early seizures in the postoperative period (Mauro, Bomprezzi et al. 2007). In a retrospective monocentric study, 78 patients with primary or secondary supratentorial brain tumors received LEV perioperatively, although only $38,5 \%$ of them had seizures preoperatively (Zachenhofer, Donat et al.), resulting in low (2.6\%) seizure frequency in the early postoperative period, as compared to literature data. Even in patients with convexity meningioma, patients with and without antiepileptic drug treatement did not differ in terms of early seizure after resection (Sughrue, Rutkowski et al.). Finally, in a randomised controled study comparing PHT and placebo, the rate of postcraniectomy study was similar (about 10\%) in the two groups (De Santis, Villani et al. 2002). This could suggest that prophylactic treatment is not recommended, even in the perioperative period despite carrying a higher risk of seizure, in patients with brain tumors but no seizures. However, additionnal risk factors for epilepsy, such as type and location of the tumor, were never taken into account in evaluating prophylactic treatment in a prospective controlled study. The question weither a subgroup of brain tumor patient could benefit from prophylactic treatment remains still unresolved.

\section{4-2- Does brain location of tumors influence prognosis?}

Repeatedly, temporal (Chaichana, Parker et al. 2009) or frontal lobe tumors have been associated with increased risk of epileptic seizure. However, could brain location of tumor influence epileptic outcome after surgery ? In a study of 37 patients 
with refractory epilepsy, long-term surgical outcomes in tumoral frontal lobe epilepsy was shown to be less favorable (35,1\% Engel class I, seizure-free, and $32,4 \%$ class II, persisting rare disabling seizures) than those in other tumoral epilepsy (overall, $70 \%$ class I) (Zaatreh, Spencer et al. 2002). The same team reported better outcome after surgery for tumoral temporal lobe epilepsy, with $87 \%$ of class I or II results (Zaatreh, Firlik et al. 2003). Other studies confirmed that tumoral temporal lobe epilepsy does not differ significantly in terms of sugical outcome from other etiologies, including hippocampal sclerosis (York, Rettig et al. 2003). Long-term prognosis in tumoral temporal lobe epilepsy is relatively favorable, but progressionfree survival rates after surgery has been estimated $97 \%$ in the 1 st year, $84 \%$ in the 2 nd year, and $80 \%$ in the 5th year, with 7 patients among 36 showing a disease progression during the follow-up (Phi and Chung 2009). In GBM patients, frontal location appears also as an additional risk for developing epilepsy (Telfeian, Philips et al. 2001). Series of patients with insular LGG also showed a good outcome after surgery, including remission of epilepsy for $82 \%$ of them (Engel class I) (Duffau, Capelle et al. 2002). Accordingly, temporal and insular lobe location, when amenable to surgery, appeared to have a better epilepsy outcome after surgery.

\section{4-3. Could time of surgery influence epilepsy outcome?}

The timing of surgery remains controversial in patients who are young, present with medically well-controled seziures, and with small low grade tumors. In a consecutive case series of patients with tumor-related refractory epilepsy, only short duration of epilepsy before surgery, single EEG focus, absence of additional hippocampal sclerosis or cortical dysplasia, transsylvian approach, other tumors than astrocytomas, and complete tumor resection were associated with improved seizure outcome (Luyken, Blumcke et al. 2003). The authors advocated early intervention, 
as should be infered also from another study, showing that preoperative seizure duration and frequency have a close relationship with the frequency of postoperative epilepsy in patients with glial tumors (Kim, Yong Ahn et al. 2004).

4-4. Could MRI changes be attributed to other factors than tumor progression? Transient MRI signal changes are reported in the context of intense seizure activity, both in children (Yang, Kim et al. 2002) and adults, even mimicking tumor (Finn, Blumenthal et al. 2007; Canas, Soares et al.) (Canas, Breia et al. 2010). Changes in tumor volume appearance has been occasionnaly associated with the use of vigabatrin in a 5-year-old female after resection of an anaplastic oligodendroglioma, with a reversal of MRI changes observed after discontinuation of the drug (Yang, Pruthi et al.). Transient MRI changes were also observed after Gamma Knife surgery for brain tumors, even leading per se to epileptic seizures (Schindler, Christ et al. 2006). Thus, seizure-related MRI changes, or other modifications due to radiotherapy or brain oedema shoud be differentiated from a recurrence or a progression of a brain tumor. These different possibilities should be kept in mind in managing such situation, since some « catastrophic » images could be transient and totally reversible.

4-5. When and how could antiepileptic drugs be withdrawn after surgical resection of low-grade gliomas?

In a systematic literature review examining 20 studies involving 773 patients, predictors of seizure freedom after surgery were Gross-total resection as compared to incomplete resection (OR 3,41), preoperative control of seizure under medication (OR 2,12) and short duration of epilepsy history (<or,= one year) $(\mathrm{OR} \mathrm{1,85)} \mathrm{(Englot,}$ Berger et al.). Patients with simple partial seizures achieved more rarely seizure 
freedom than patients with complex partial seizures (OR 0,46). According to this systematic review, the critical factor allowing antiepileptic drugs withdrawal appeared to be the gross-total resection of the tumour. In a case series report, low presurgery seizure frequency and tumor etiology were predictors for favourable postsurgery outcome in extratemporal lobe epilepsy (Boesebeck, Janszky et al. 2007). In adults patients with tumour-related refratory temporal lobe epilepsy, ganglioglioma and astrocytoma were equally represented in a case series from one neurosurgical center, and the outcome was considered favorable (Bauer, Dobesberger et al. 2007). In children, tumor (or angioma-) associated temporal lobe epilepsies were associated with a better outcome after surgery (79\% Engel Class I, seizure freedom) as compared to children with non tumour temporal lobe epilepsies (50\% Engel Class I) (Benifla, Rutka et al. 2008). However, some TLE children series did not found a such high rate of brain tumors, cortical dysplasia and hippocampal sclerosis being the most frequently evidenced findings after surgery (Bocti, Robitaille et al. 2003). In another pediatric case series, regardless surgery was done or not, AED withdrawal was associated with a low seizure recurence $(27 \%)$ during a median followup duration of 2.3 years (range 0,4 to 15 years) (Khan and Onar 2006). Thus, withdrawal of AEDs after successful surgery (pending what success is) should be individualized, and the risk of seizure reccurrence balanced with the expected benefit. According to epilepsy surgery current view, a delay of two years after surgery appears to be reasonnable, but, again, different factors (type and location of seizures, refractoriness of the presurgical epilepsy) should be taken into account.

\section{4-6. What is the role of EEG in clinical management of BTE ?}

It is of current practice to perform EEG recordings in the setting of patients with brain 
tumor, but what is expected from this ? It is well-known that epileptiform discharges are not pathognomonique for epilepsy and could be observed in subjects without any seizures (Sam and So 2001). Moreover, it has been shown that interictal « injury » spikes eventually recorded in the postoperative period are not associated with an increased risk of seizures (Schwartz, Bazil et al. 2000),a result further confirmed in patients with meningioma undergoing surgery (Rothoerl, Bernreuther et al. 2003). Thus, EEG is not helpful either for the diagnosis of epilepsy (which is clinically argumented and attributed to the presence of the brain tumor, when not better explained by an acute symptomatic etiology), the prediction of seizure in the specific setting of brain tumor, or the the therapeutical management, aldhouth its contribution to withdrawal decision should be evaluated. However, in a pediatric study, EEG slow wave activity was correlated with a poor epilepsy outcome (Khan, Hunt et al. 2005). To summarize, EEG value in brain tumor appears to be relatively weak in terms of diagnosis and prognosis, but in some clinical situation, such as suspected non convulsive status epilepticus or encephalopathy, its contribution is invaluable (Niedermeyer 2003), as examplified in the context of metastatis (Blitshteyn and Jaeckle 2006).

\section{Conclusion}

Even more than in other contexts, epilepsy in patients with brain tumor represents a therapeutical challenge. A substantial rate of drug-resistance, possible interference with chemotherapy, and overall, severe impact on quality of life, even in patients with well-controlled tumor, are potential source of concern and debate and should promote a real individualization of the therapy. In clinical practice, but also from a 
pathophysiological point of view, many issues remain questionnable, such as timing of surgery and withdrawal of antiepileptic drugs, adequation between lesionectomy and epilepsy surgery, role of peritumoral tissue, or the role of neuroimagery and neurophysiology in the clinical management. Further high-quality studies are mandatory to improve the clinical care of these patients. 


\section{References}

Alanis-Guevara I, Pena E, Corona T, Lopez-Meza E, Lopez-Gomez M. (2005) Sleep disturbances, socioeconomic status, and seizure control as main predictors of quality of life in epilepsy. Epilepsy Behav 7:481-5

Alexiou GA, Varela M, Sfakianos G, Prodromou N. (2010) Benign lesions accompanied by intractable epilesy in children. J Child Neurol 24: 697-700 Armstrong TS, Choi S, Walker J, Gilbert MR (2010) Seizure risk in brain tumor patients with conversion to generic levetiracetam. J Neurooncol 98:137-41 Auriel E, Landov H, Blatt I, Thietler J, Gandelman-Marton R, Chistik V et al. (2009) Quality of life in seizure-free patients with epilepsy on monotherapy. Epilepsy Behav 14: $130-3$

Baker GA, Jacoby A, Buck D, Stalgis C, Monnet D. (1997) Quality of life of people with epilepsy : a European study. Epilepsia 38:353-62

Bauer R, Dobesberger J, Unterhofer C, Unterberger I, Walser G, Bauer G, Trinka E, Ortler M. (2007) Outcome of adult patients with temporal lobe tumours and medically refractory focal epilepsy. Acta Neurochir (Wien) 149: 1211-6

Beaumont A, Whittle IR (2000) The pathogenesis of tumour associated epilepsy. Acta Neurochir (Wien) 142: 1-15

Beghi E, Carpio A, Forsgren L, Hesdorffer DC, Malmgren K, Sander JW, Tomson T, Hauser WA. (2010) Recommendation for a definition of acute symptomatic seizure. Epilepsia 51: 671-5

Benifla M, Rutka JT, Otsubo H, Lamberti-Pasculli M, Elliott I, Self E et al. (2008) Long-term seizure and social outcomes following temporal lobe surgery for intractable epilepsy during childhood. Epilepsy Res 82:133-8 
Black PM (1991a) Brain Tumors. Part 1. N Engl J Med 324: 1471-6

Black PM (1991b) Brain Tumors. Part 2. N Engl J Med 324: 1555-64

Blitshteyn S, Jaeckle KA (2006) Non convulsive status epilepticus in metastatic CNS disease. Neurology 66:1261-3

Blumcke I (2009) Neuropathology of focal epilepsies : a critical review. Epilepsy Behav 15: 34-9

Bocti C, Robitaille Y, Diadori P, Lortie A, Mercier C, Bouthillier A, Carmant L. (2003) The pathological basis of temporal lobe epilepsy in childhood. Neurology 60: 191-5 Boesebeck F, Janszky J, Kellinghaus C, May T, Ebner A. (2007) Presurgical seizure frequency and tumoral etiology predict the outcome after extratemporal epilepsy surgery. J Neurol 254: 996-9

Boylan LS, Flint LA, Labovitz DL, Jackson SC, Starner K, Devinsky O. (2004) Depression but not seizure frequency predicts quality of life in treatment-resistant epilepsy. Neurology 62: 258-61

Byrne TN, Cascino TL, Posner JB. (1983) Brain metastatis from melanoma. J Neurooncol 1:313-7

Canas N, Breia P, Soares P, Saraiva P, Calado S, Jordão C, Vale J. (2010) The electroclinical-imagiological spectrum and long-term outcome fo transient periictal MRI abnormalities. Epilepsy Res 91: 240-52

Canas N, Soares P, Calado S, Pestana R, Ribeiro C, Vale J. (2010) Pathophysiology and long-term outcome of reversible tumor-like lesions induced by presenting status epilepticus. J Neuroimaging $40: 169-174$

Chaichana KL, Parker SL, Olivi A, Quinones-Hinojora A. (2009) Long-term seizure outcomes in adult patients undergoing primary resection of malignant brain astrocytomas. J Neurosurg $111:$ 282-92 
Chang EF, Potts MB, Keles GE, Lamborn KR, Chang SM, Barbaro NM, Berger MS. (2008) Seizure characteristics and control following resection in 332 patients with low-grade glioma. J Neurosurg $108: 227-35$

Chen C, Shih YH, Yen DJ, Lirnq JF, Guo YC, Yu HY, Yiu CH. (2003) Olfactory auras in patients with temporal lobe epilepsy. Epilepsia $44: 257-60$

Conti G, Palma E, Roseti C, Lauro C, Cipriani R, de Groot M, Aronica E, Limatola C. (2011) Anomalous level of $\mathrm{Cl}$ - transporters cause a decrease of GABAergic inhibition in human peritumoral epileptic cortex. Doi : 10.1111/j.1528-1167.2011.03111.x (Epub ahead of print)

Cramer IA (2002) Mood disorders are linked to health-related quality of life in epilepsy. Epilepsy Behav $3: 491-2$

Danfors TD, Ribom D, Berntsson SG, Smits A. (2009) Epileptic seizures and survival in early disease of grade 2 gliomas. Eur J Neurol $16: 823-31$

De Santis A, Villani R, Sinisi M, Stocchetti N, Perucca E. (2002) Add-on phenytoin fails to prevent early seizures after surgery for supratentorial brain tumors : a randomized controlled study. Epilepsia $2002 ; 43: 175-182$

Deepak D, Daousi C, Javadpour M, MacFarlane IA. (2007) Macroprolactinomas and epilepsy. Clin Endocrinol (Oxf) 66 :503-7

Duffau H, Capelle L, Lopes M, Bitar A, Sichez JP, van Effenterre R. (2002) Medically intractable epilepsy from insular low-grade gliomas : improvement after an extended lesionectomy. Acta Neurochir (Wien) $144:$ 563-72

Dupont S. (2008) Epilepsie et Tumeurs cérébrales. Rev Neurol (Paris) 164 : 517-522 Englot DJ, Berger MS, Barbaro NM, Chang EF. (2011) Predictors of seizure freedom after resection of supratentorial low-grade gliomas. J Neurosurg $115: 240-4$ Finn MA, Blumenthal DT, Salsman KL, Jensen RL. (2007) Transient postictal MRI 
changes in patients with brain tumors may mimic disease progression. Surg Neurol $67: 246-250$

Fisher RS, van Emde Boas W, Blume W, Elger C, Genton P, Lee P, Engel J Jr. (2005) Epileptic seizures and epilepsy : definitions proposed by the International League Against Epilepsy (ILAE) and the International Bureau for Epilepsy (IBE). Epilepsia $46: 470-2$

Forsyth PA, Weaver S, Fulton D, Brasher PM, Sutherland G, Stewart D, Hagen NA, Barnes P, Cairncross JG, DeAngelis LM. (2003) Prophylactic anticonvulsants in patients with brain tumour. Can J Neurol Sci 30 : 106-12

Gaggero R, Consales A, Fazzini F, Mancardi MM, Baglietto MG, Nozza P, et al. (2009) Epilepsy associated with supratentorial brain tumors under 3 years of life. Epilepsy Res 87 : 184-9

Giulioni M, Galassi E, Zucchelli M, Volpi L. (2005) Seizure outcome of lesionectomy in glioneuronal tumors associated with epilepsy in children. J Neurosurg 102 (Suppl.3) : 288-93

Giulioni M, Gardella E, Rubboli G, Roncaroli F, Zucchelli M, Bernardi B, Tassinari CA, Calbucci F. (2006) Lesionectomy in epileptogenic gangliogliomas : seizure outcome and surgical results. J Clin Neurosci $13: 529-35$

Giulioni M, Rubboli G, Marucci G, Martinoni M, Volpi L, Michelucci R, et al. (2009) Seizure outcome of epilepsy surgery in focal epilepsies associated with temporomesial glioneuronal tumors : lesionectomy compared with tailored resection. J Neurosurg $111: 1275-82$

Glantz MJ, Cole BF, Forsyth PA, Recht LD, Wen PY, Chamberlain MC, Grossman SA, Cairncross JG. (2000) Practice parameter : anticonvulsant prophylaxis in patients with newly diagnosed brain tumors. Report of the Quality Standards 
Subcommittee of the American Academy of Neurology. Neurology 54 : 3394-402 Hamilton W, Kernick D (2007) Clinical features of primary brain tumours : a casecontrol study using electronic primary care records. Br J Gen Pract 57 : 695-9 Hwang SL, Lin CL, Lee KS, Lieu AS, Kuo TH, Chang CZ, et al. (2004) Factors influencing seizures in adult patients with supratentorial astrocytic tumors. Acta Neurochir (Wien) $146: 589-94$

lannelli A, Pieracci N (2008) Tumors in the temporal horn of the lateral ventricle as a cause of epilepsy. J Child Neurol $23: 315-20$

Ibrahim K, Appleton R (2004) Seizures as the presenting symptom of brain tumours in children. Seizure $13: 108-12$ Im SH, Chung CK, Cho BK, Lee SK (2002) Supratentorial ganglioglioma and epilepsy : postoperative seizure outcome. J Neurooncol 57 : 59-66

Khan RB, Hunt DL, Boop FA, Sanford RA, Merchant TE, Gajjar A, Kun LE. (2005) Seizures in children with primary brain tumors : incidence and long-term outcome. Epilepsy Res 64 : 85-91

Khan RB, Onar A (2006) Seizure recurrence and risk factors after antiepilepsy drug withdrawal in children with brain tumors. Epilepsia $47: 375-9$

Kim OJ, Yong Ahn J, Chung YS, Chung SS, Lee KS, Choi JU, Lee BI (2004) Significance of chronic epilepsy in glial tumors and correlation with surgical strategies. J Clin Neurosci $11: 702-5$

Klein M, Engelberts NH, van der Ploeg HM, Kasteleijn-Nolst Trenité DG, Aaronson NK, Taphoorn MJ et al. (2003) Epilepsy in low-grade gliomas : the impact on cognitive function and quality of life. Ann Neurol $54: 514-20$ Kohling R, Senner V, Paulus W, Speckmann EJ. (2006) Epileptiform activity preferentially arises outside tumor invasion zone in glioma xenotransplants. 
Neurobiol Dis 22 : 64-75

Krouwer HG, Pallagi JL, Graves NM. (2000) Management of seizures in brain tumor patients at the end of life. J Palliat Med $3: 465-75$

Lagerwaard FJ, Levendag PC, Nowak PJ, Eijkenboom WM, Hanssens PE, Schmitz PI. (1999) Identification of prognostic factors in patients with brain metastases : a review of 1292 patients. Int J Radiat Oncol Biol Phys 43 : 795-803

Lee JW, Wen PY, Hurwitz S, Black P, Kesari S, Drappatz J et al. (2010) Morphological characteristics of brain tumors causing seizures. Arch Neurol 67 : 33642

Liigant A, Haldre S, Oun A, Linnamagi U, Saar A, Asser T, Kaasik AE. (2001)

Seizure disorders in patients with brain tumors. Eur Neurol $45: 46-51$

Lim DA, Tarapore P, Chang E, Burt M, Chakalian L, Barbaro N et al (2009) Safety and feasibility of switching from phenytoin to levetiracetam monotherapy of gliomarelated seizure control following craniotomy : a randomized phase II pilot study. $\mathrm{J}$ Neurooncol $93: 349-54$

Loddenkemper T, Morris HH 3rd, Diehl B, Lachhwani DK. (2006) Intracranial lipomas and epilepsy. J Neurol $253: 590-3$

Louis DN, Ohgaki H, Wieslter OF, Cavenee WK, Burger PC, Jouvet A, Scheithauer BW, Kleihues P. (2007) The 2007 WHO classification of tumours of the central nervous system. Acta Neuropathol 114 : 97-109. Erratum in : Acta Neuropathol $2007 ; 114: 547$

Luyken C, Blumcke I, Fimmers R, Urbach H, Elger CE, Wiestler OD, Schramm J. (2003) The spectrum of long-term epilepsy-associated tumors : long-term seizure and tumor outcome and neurosurgical aspects. Epilepsia $44: 822-30$ Lwu S, Hamilton MG, Forsyth PA, Cairncross JG, Parney IF. (2010) Use of peri- 
operative anti-epileptic drugs in patients with newly diagnosed high grade malignant glioma : a single center experience. J Neurooncol 96 : 403-8

Lynam LM, Lyons MK, Drazkowski JF, Sirven JI, Noe KH, Zimmerman RS, Wilkens JA. (2007) Frequency of seizures in patients with newly diagnosed brain tumors : a retrospective review. Clin Neurol Neurosurg 109 : 634-8

Mangano FT, McBride AE, (2002) Brain Tumors and Epilepsy. In Managing Epilepsy and co-existing disoder. AB Ettinger and O Devinsky Eds, Butterworth-Heinemann : 175-194

Marchi N, Angelov L, Masaryk T, Fazio V, Granata T, Hernandez N et al. (2007) Seizure-promoting effect of blood-brain barrier disruption. Epilepsia 48 :732-42 Marson AG, Al-Kharushi AM, Alwaidh M, Appleton R, Baker GA, Chadwick DW et al. (2007) The SANAD study of effectiveness of carbamazepine, gabapentin, lamotrigine, oxcarbazepine, or topiramate for treatment of partial epilepsy : an unblinded randomised controlled trial. Lancet $369: 1000-15$

Maschio M, Albani F, Baruzzi A, Zarabla A, Dinapoli L, Pace A, Pompili A, Carapella CM, Occhipinti E, Jandolo B. (2006) Levetiracetam therapy in patients with brain tumour and epilepsy. J Neurooncol $80: 97-100$

Maschio M, Dinapoli L, Gomellini S, Ferraresi V, Sperati F, Vidiri A, Muti P, Jandolo B. (2010) Antiepileptics in brain metastases : safety, efficacy and impact on life expectancy. J Neurooncol $98: 109-16$

Maschio M, Dinapoli L, Saveriano F, Pompili A, Carapella CM, Vidiri A, Jandolo B. (2009) Efficacy and tolerability of zonisamide as add-on in brain tumor-related epilepsy : preliminary report. Acta Neurol Scand $120: 210-2$

Maschio M, Dinapoli L, Sperati F, Pace A, Fabi A, Vidiri A, Muti P. (2011) Levetiracetam monotherapy in patients with brain tumor-related epilepsy : seizure 
control, safety, and quality of life. J Neurooncol (In Press)

Maschio M, Dinapoli L, Vidiri A, Muti P. (2010) Rash in four patients with brain tumorrelated epilepsy in monotherapy with oxcrabazepine, during radiotherapy. J Neurol $257: 1939-40$

Maschio M, Dinapoli L, Vidiri A, Pace A, Fabi A, Pompili A, Carapella MC, Jandolo B. (2009) The role of side effects play in the choice of antiepileptic therapy in braintumor related epilepsy : a comparative study on traditional antiepileptic drugs versus oxcarbazepine. J Exp Clin Cancer Res $28: 60$

Maschio M, Dinapoli L, Mingoia M, Sperati F, Pace A, Pompili A, Carapella CM, Vidiri A, Muti P. (2011) Lacosamide as add-on in brain tumor-related epilepsy : preliminary report on efficacy and tolerability. J Neurol (In press)

Mauro AM, Bomprezzi C, Morresi S, Provinciali L, Formica E, lacoangeli M, Scerrati M. (2007) Prevention of early postoperative seizures in patients with primary brain tumours : preliminary experience with oxcarbazepine. J Neurooncol $81: 279-85$ Mikkelsen T, Paleologos NA, Robinson PD, Ammirati M, Andrews DW, Asher AL et al. (2010) The role of prophylactic anticonvulsants in the management of brain metastases : a systematic review and evidence-based clinical practice guideline. $J$ Neurooncol. 96 :97-102

Mitsueda-Ono T, Ikeda A, Inouchi M, Takaya S, Matsumoto R, Hankawa T et al. (2011) Amygdala enlargement in patients with temporal lobe epilepsy. J Neurol Neurosurg Psychiatry $82: 652-7$

Miyagawa T, Sotero M, Avellino AM, Kuratani J, Saneto RP, Ellenbogen RG, Ojemann JG. (2007) Apnea caused by mesial temporal lobe mass lesions in infants : report of 3 cases. J Child Neurol $22: 1079-83$

Newton HB, Dalton J, Goldlust S, Pearl D. (2007) Retrospective analysis of the 
efficacy and tolerability of levetiracetam in patients with metastatic brain tumors. $\mathrm{J}$ Neurooncol 84 : 293-6

Newton HB, Goldlust SA, Pearl D. (2006) Retrospective analysis of the efficacy and tolerability of levetiracetam in brain tumor patients. J Neurooncol 78 :99-102 Ngo L, Nei M, Glass J. (2006) Temozolomide treatment of refractory epilepsy in a patient with an oligodendroglioma. Epilepsia 47 : 1237-8 Niedermeyer E. (2003) The clinical relevance of EEG interpretation. Clin Electroencephalogr 34 : 93-8

Novy J, Stupp R, Rossetti AO (2009) Pregabalin in patients with primary brain tumors and seizures : a preliminary observation. Clin Neurol Neurosurg $111: 171-3$ Oberndorder S, Piribauer M, Marosi C, Lahrmann H, Hitzenberger P, Grisold W. (2005) P450 enzyme inducing and non-enzyme inducing antiepileptics in glioblastoma patients treated with standard chemotherapy. J Neurooncol 72 : 255-60 Pace A, Di Lorenzo C, Guariglia L, Jandolo B, Carapella CM, Pompili A. (2009) End of life issues in brain tumor patients. J Neurooncol $91: 39-43$

Park YS, Kim DS, Shim KW, Kim JH, Choi JU. (2008) Factors contributing to resectability and seizure outcomes in 44 patients with ganglioglioma. Clin Neurol Neurosurg $110: 667-73$

Partap S, Fisher PG (2009) Levetiracetam for seizures in children with brain tumors and other cancers. Pediatr Blood Cancer $52: 288-9$

Pasquier B, Peoc'h M, Fabre-Bocquentin B, Bensaadi L, Pasquier D, Hoffmann D, Kahane P, Tassi L, Le Bas JF, Benabid AL. (2002) Surgical pathology of drugresistant partial epilepsy. A 10-year-experience with a series of 327 consecutive resections. Epileptic Disord 4 : 99-119

Phi JH, Chung CK (2009) Brain tumors in the mesial temporal lobe : long-term 
outcome. Neurosurg Focus 27 :E5

Preusser M, de Ribeaupierre S, Wohrer A, Erridge SC, Hegi M, Weller M, Stupp R. (2011) Current concepts and management of glioblastoma. Ann Neurol 70 :9-21

Pugh MJ, Knoefel JE, Mortensen EM, Amuan ME, Berlowitz DR, Van Cott AC. (2009) New-onset epilepsy risk factors in older veterans. J Am Geriatr Soc. 57 : 23742

Rosati A, Buttolo L, Stefini R, Todeschini A, Cenzato M, Padovani A. (2010) Efficacy and safety of levetiracetam in patients with glioma : a clinical prospective study. Arch Neurol 67 : 343-6

Rosati A, Marconi S, Pollo B, Tomassini A, Lovato L, Maderna E et al. (2009) Epilepsy in glioblastoma multiforme : correlation with glutamine synthetase levels. J Neurooncol $93: 319-24$

Rosati A, Tomassini A, Pollo B, Ambrosi C, Schwarz A, Padovani A, Bonetti B. (2009) Epilepsy in cerebral glioma : timing of appearance and histological correlations. J Neurooncol $93: 395-400$

Rosenow F, Reif PS, Haag A, Schmidt K, Strik H. (2010) Correlation of enzymeinducing anticonvulsant use with outcome of patients with glioblastoma. Neurology $74: 1330-1$

Rossetti AO, Kaplan PW (2010) Seizure semiology : an overview of the 'inverse problem'. Eur Neurol 63 : 3-10

Rossetti AO, Stupp R. (2011) Epilepsy in brain tumor patients. Curr Opin Neurol 23 : 603-9

Rossi R, Figus A, Corraine S. (2010) Early presentation of de novo high grade glioma with epileptic seizures : electroclinical and neuroimaging findings. Seizure $19: 470-4$ Rothoerl DR, Bernreuther D, Woertgen C, Brawanski A. (2003) The value of routine 
electrencephalographic recordings in predicting postoperative sezures associated with meningioma surgery. Neurosurg Rev 26 : 108-112

Ruban D, Byrne RW, Kanner A, Smith M, Cochran EJ, Roh D, Whisler WW. (2009) Chronic epilepsy associated with temporal tumors : long-term surgical outcome. Neurosurg Focus 27 : E6

Ruggiero A, Rizzo D, Mastrangelo S, Battaglia D, Attina G, Riccardi R. (2010) Interactions between antiepileptic and chemotherapeutic drugs in children with brain tumors : is it time to change treatment ? Pediatr Blood Cander 54 : 193-8 Sam MC, So EL (2001) Significance of epileptiform discharges in patients without epilepsy in the community. Epilepsia 42 : 1273-8

Schaller B, Ruegg SJ (2003) Brain tumor and seizures : pathophysiology an dits implications for treatment revisited. Epilepsia 44 : 1223-32

Schindler K, Christ ER, Mindermann T, Wieser HG. (2006) Transient MR changes and symptomatic epilepsy following gamma knife treatment of a residual $\mathrm{GH}$ secreting pituitary adenoma in the cavernous sinus. Acta Neurochir (Wien) 148 : 9038

Schwartz TH, Bazil CW, Forgione M, Bruce JN, Goodman RR (2000) Do reactive post-resection « injury » spikes exist ? Epilepsia 41 : 1463-8

Shamji MF, Fric-Shamji EC, Benoit BG (2009) Brain tumors and epilepsy : pathophysiology of peritumoral changes. Neurosurg Rev $32: 275-84$ Sikkel MB, Batrick N (2007) Episodic asystole and apnoea as the presenting features of a diffuse glioma. Resuscitation 73 : 304-6

Sinclair DB, Wheatley M, Aronyk K, Hao C, Snyder T, Colmers W, McKean JD. (2001) Pathology and neuroimaging in pediatric temporal lobectomy for intractable epilepsy. Pediatr Neurosurg 35 : 239-246 
Siomin V, Angelov L, Li L, Vogelbaum MA (2005) Results of a survey of neurosurgical practice patterns regarding the prophylactic use of anti-epilepsy drugs in patients with brain tumors. J Neurooncol $74: 211-5$

Sirven JI, Wingerchuk DM, Drazkowski JF, Lyons MK, Zimmerman RS. (2004) Seizure prophylaxis in patients with brain tumors : a meta-analysis. Mayo Clin Proc. $79: 1489-94$

Smits A, Duffau H. (2011) Seizures and the natural history of word heath organisation Grade II gliomas : A review. Neurosurgery 68 :1326-1333 Soeder BM, Gleissner U, Urbach H, Clusmann H, Elger CE, Vincent A, Bien CG. (2009) Causes, presentation and outcome of lesional adult onset mediotemporal lobe epilepsy. J Neurol Neurosurg Psychiatry $80: 894-9$

Soffietti R, Baumert BG, Bello L, von Deimling A, Duffau H, Frenay M et al. (2010) Guidelines on management of low-grade gliomas : report of an EFNS-EANO Task Force. Eur J Neurol $17: 1124-33$

Sogawa Y, Kan L, Levy AS, Maytal J, Shinnar S. (2009) The use of antiepileptic drugs in pediatric brain tumor patients. Pediatr Neurol 41 : 192-4

Stephen LJ, Kwan P, Brodie MJ (2001) Does the cause of localisation-related epilepsy influence the response to antiepileptic drug treatment? Epilepsia $42: 357$ 62

Striano S, Striano P, Coppola A, Romanelli P. (2009) The syndrome gelastic seizures-hypothalamic hamartoma : severe, potentially reversible epilepsy. Epilepsia 50 (Suppl.5) : 62-5

Sughrue ME, Rutkowski MJ, Chang EF, Shangari G, Kane AJ, McDermott MW, Berger MS, Parsa AT. (2011) Postoperative seizures following the resection of convexity meningiomas : are prophylactic anticonvulsants indicated ? J Neurosurg 
$114: 705-9$

Taillandier L, Duffau H (2009) Epilepsy and insular Grade II gliomas : an interdisciplinary point of view from a retrospective monocentric series of 46 cases. Neurosurg Focus $27:$ E8

Tassi L, Meroni A, Deleo F, Villani F, Mai R, Russo GL et al. (2009) Temporal lobe epilepsy : neuropathological and clinical correlations in 243 surgically treated patients. Epileptic disord $11: 281-92$

Tefleian AE, Philips MF, Crino PB, Judy KD. (2001) Postoperative epilepsy in patients undergoing craniotomy for glioblastoma multiforme. J Exp Clin Cancer Res $20: 5-10$

Tremont-Lukats IW, Ratilal BO, Armstrong T, Gilbert MR. (2008) Antiepileptic drugs for preventing seizures in people with brain tumors. Cochrane Database Syst Rev CD004424

Usery JB, Michael LM 2nd, Sills AK, Finch CK. (2010) A prospective evaluation and literature review of levetiracetam use in patients with brain tumors and seizures. $J$ Neurooncol 99 : 251-60

Van Breemen MS, Rijsman RM, Taphoorn MJ, Walchenbach R, Zwinkels H, Vecht CJ (2009) Efficacy of anti-epileptic drugs in patients with gliomas and seizures. J Neurol $256: 1519-26$

Van Breemen MS, Wilms EB, Vecht CJ (2007) Epilepsy in patients with brain tumours : epidemiology, mechanisms, and management. Lancet Neurol 6 : 421-30 Van der Sluijs BM, Renier WO, Kappelle AC. (2004) Brain tumour as a rare cause of cardiac syncope. J Neurooncol 67 : 241-4

Van Veelen ML, Avezaat CJ, Kros JM, van Putten W, Vecht C (1998) Supratentorial low grade astrocytoma : prognostic factors, dedifferentiation, and the issue of early 
versus late surgery. J Neurol Neurosurg Psychiatry $64: 581-7$

Vecht CJ, Van Breemen M. (2006) Optimizing therapy of seizures in patients with brain tumors. Neurology 67 (Suppl 4) : S10-3

Vecht CJ, Wilms EB (2010) Seizures in low- and high-grade gliomas : current management and future outlook. Expert Rev Anticancer Ther $10: 663-9$ Wagner GL, Wilms EB, van Donselaar CA, Vecht CJ (2003) Levetiracetam : preliminary experience in patients with primary brain tumours. Seizure $12: 585-6$ Wen PY, Schiff D, Kesari S, Drappatz J, Gigas DC, Doherty L. (2006) Medical management of patients with brain tumors. J Neurooncol $80: 313-32$ Wick W, Menn O, Meisner C, Steinbach J, Hermisson M, Tatagiba M, Weller M. (2005) Pharmacotherapy of epileptic seizures in glioma patients : who, when, why and how long ? Onkologie 28 : 391-6

Wrensch M, Minn Y, Chew T, Bondy M, Berger MS (2002) Epidemiology of primary brain tumors : current concepts and review of the literature. Neuro Oncol $4: 278-99$ Xiao B, Huang ZL, Zhang H, Liu YS, Yuan XR, Zhang N, et al. (2004) Aetiology of epilepsy in surgically treated patients in China. Seizure $13: 322-7$

Yang I, Chang EF, Han SJ, Barry JJ, Fang S, Tihan T, Barbaro NM, Parsa AT. (2011) Early surgical intervention in adult patients with ganglioglioma is associated with improved clinical seizure outcomes. J Clin Neurosci $18: 29-33$ Yang KH, Kim DS, Choi JU. (2002) The reversible focal MRI abnormalities in complex partial seziure : technical instruction. Childs Nerv Syst. $18: 722-4$ Yang T, Pruthi S, Geyer JR, Ojeman JG. (2010) MRI changes associated with vigabatrin treatment mimicking tumor progression. Pediatr Blood Cander 55 : 1221-3 York MK, Rettig GM, Grossman RG, Hamilton WJ, Armstrong DD, Levin HS, Mizrahi EM (2003) Seizure control and cognitive outcome after temporal lobectomy : a 
comparison of classic Ammon's horn sclerosis, atypical mesial temporal sclerosis and tumoral pathologies. Epilepsia $44: 387-98$

Zaatreh MM, Firlik KS, Spencer DD, Spencer SS. (2003) Temporal lobe tumoral epilepsy : characteristics and predictors of surgical outcome. Neurology 61 : 636-41 Zaatreh MM, Spencer DD, Thompson JL, Blumenfeld H, Novotny EJ, Mattson RH, Spencer SS. (2002) Frontal lobe tumoral epilepsy : clinical, neurophysiologic features and predictors of surgical outcome. Epilepsia $43: 727-33$

Zachenhofer I, Donat M, Oberndorfer S, Roessler K. (2011) Perioperative levetiracetam for prevention of seizures in supratentorial brain tumor surgery. $\mathrm{J}$ Neurooncol $101: 101-6$

Zimm S, Wampler GL, Stablein D, Hazra T, Young HF. (1981) Intracerebral metastases in solid-tumor patients : natural history and results of treatment. Cancer 48 : 384-94 


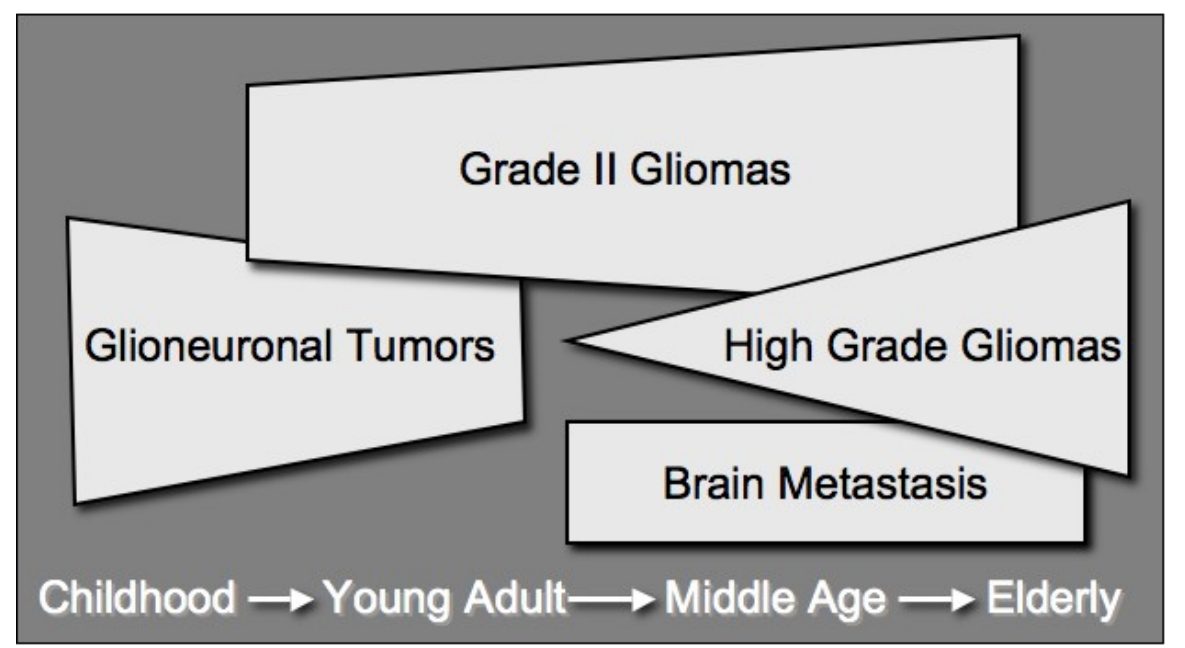

Figure 1 : Schematic representation of the respective epilepsy incidences along life-long time in different types of brain tumors (including a representation of their proportions as revealing or long-term epilepsy)

Figure 1 : représentation schématique des incidences de l'épilepsie au cours des différents types de tumeurs cérébrales au cours des âges (avec une mention de l'incidence respective comme mode de révélation ou complication secondaire) 


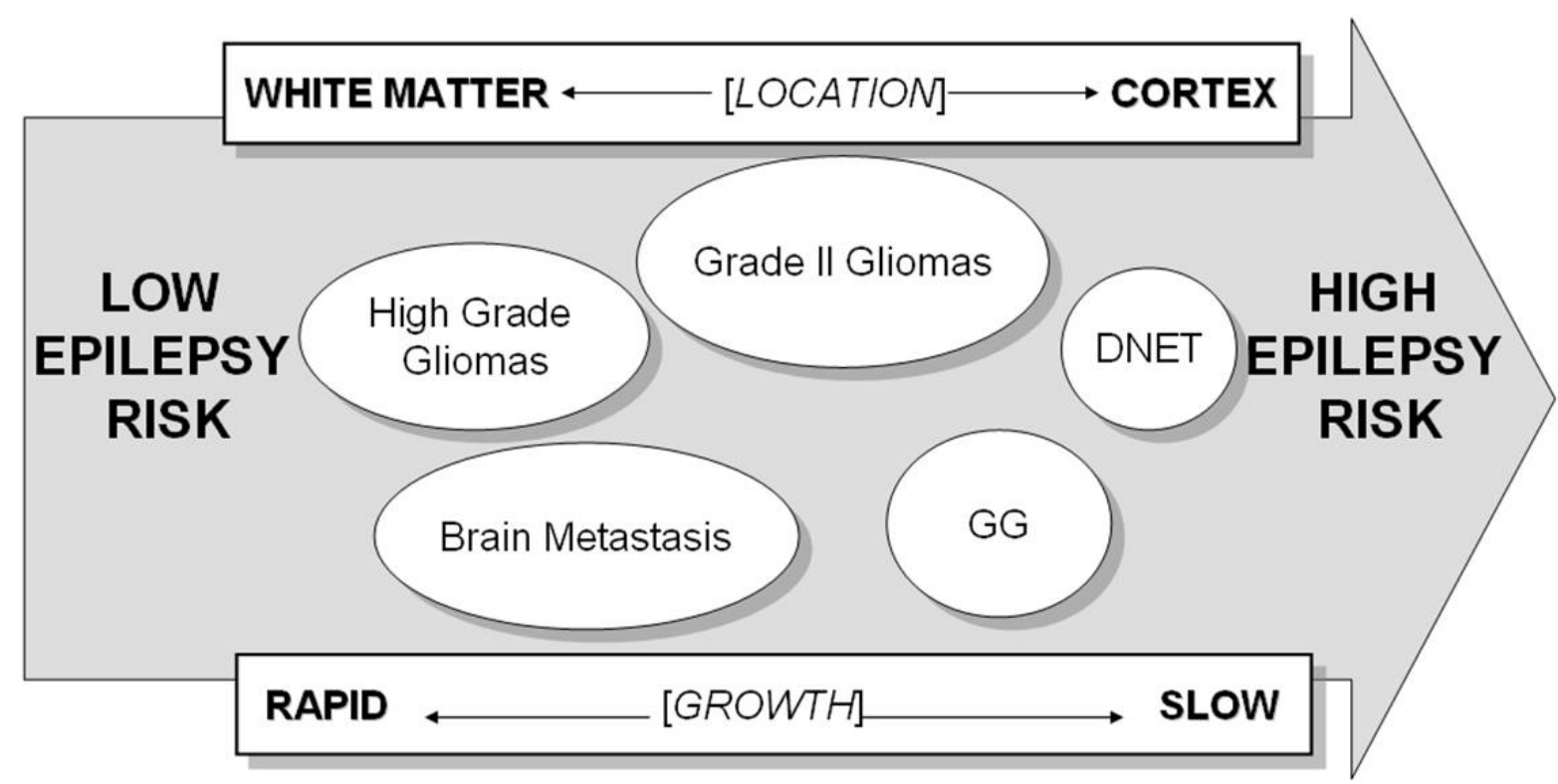

Figure 2: Risk of epilepsy relative to growth, location and type of brain tumor Figure 2: Evaluation du risque épileptique en fonction de la vitesse de croissance, de la localisation et du type de tumeur cérébrale 


\begin{tabular}{|l|l|l|}
\hline Type of Brain Tumor & Presenting sign & Long term incidence \\
\hline DNET & $100 \%$ & $100 \%$ \\
\hline Ganglioglioma & $60-80 \%$ & $80-90 \%$ \\
\hline Grade II Glioma & $70-90 \%$ & $70-90 \%$ \\
\hline Glioblastoma multiforme & Rare & $30-80 \%$ \\
\hline Metastasis & $20 \%$ & $20-30 \%$ \\
\hline Meningiomas & & $30-60 \%$ \\
\hline Lymphomas & Rare & $10 \%$ \\
\hline
\end{tabular}

Table 1 : respective incidence of epilepsy, as presenting sign, or during tumor course, depending on brain tumor type.

Tableau 1 : incidence de l'épilepsie en fonction du type de tueur. 